\title{
Atmospheric Deposition of Trace Elements on Carbonate Material of Historic Buildings in Two Urban Sites
}

\author{
K. Vidović ${ }^{1}$, P. Orlović-Leko ${ }^{2}$, I. Ciglenečki ${ }^{3}$, D. Nekić ${ }^{2}$ \\ ${ }^{1}$ National Institute of Chemistry, Hajdrihova 19, 1000 Ljubljana, Slovenia \\ ${ }^{2}$ University of Zagreb, Faculty of Mining, Geology and Petroleum Engineering, Pierottijeva 6, 10000 \\ Zagreb, Croatia \\ ${ }^{3}$ Center of Marine and Environmental Research, Ruđer Bošković Institute, Bijenička cesta 54, 10000 \\ Zagreb, Croatia \\ kristijan.vidovic@ki.si
}

\begin{abstract}
Quantifying the anthropogenic metals concentrations in black crust (BCs) developing on the surface of historic buildings, gives a general overview of environmental pollution. In this study, trace elements concentrations were determined by ICP-MS in the samples of BCs from the monuments in two urban cities: Zagreb (Croatia) and Jajce $(\mathrm{B} \& \mathrm{H})$. Higher concentration of trace metals in the sample from Jajce than those from Zagreb, can be associated to the age of the monument and to the different pollution sources.
\end{abstract}

Key words: Black crust, trace metals, ICP-MS, enrichment factor, air pollution

\section{Introduction}

Buildings can act as repositories of different kind of atmospheric pollutions, which accumulate at the surfaces in zones frequently, soaked by rainwater but are not washed out. In these areas thick black crust (BCs) deposits can be found, which contribute to soling of stone surfaces [1]. In other words building materials are passive samplers of pollution that affected the ecosystem over the years [2]. Nowdays the building materials has been degraded more than in the past, which suggests that air pollution is one of the most important cause of this process [3,4]. Several authors [5] have demonstrated that the analysis of $\mathrm{BCs}$ reveals the changing pollution pattern over time. There are different reasons for studying BCs. The two main reasons are the air pollution and building protection. This work will be focused on the air pollution. Today's main causes of urban atmospheric pollutions are the atmospheric aerosols derived from different combustion processes. Fossil fuel combustion by industrial facilities and vehicular engines is a major source of anthropogenic particulate emissions into the atmosphere [6]. The evaluation of the geochemical composition, in terms of trace elements such as trace metals in the BCs developing on monuments, provides useful information on pollution sources [7]. Traffic is the main source of several polluting elements that can be considered as emerging contaminants. Different toxic and potentially toxic compounds emitted by wear from vehicles and exhausts, together with primary and secondary particles from other anthropogenic sources are deposited and accumulated on the stone monuments. In this work quantitative analysis of trace metals was carried out by inductively coupled plasma mass spectrometry (ICP-MS) which is a very sensitive technique capable to analyze a high number of trace and rare earth elements. Trace element concentrations were determined in the BCs from the three monuments: Cathedral in Zagreb, Croatia, St. Mary Church and "Bear tower" in Jajce, B\&H, and in the limestone from the quarries, where the stone for the monuments was exploited.

\section{Materials and methods}

Samples of BCs were collected from the surfaces of three different historical monuments located at different urban sites. Different kind of pollution can be considered for each site. The Cathedral from Zagreb (Fig. 1) is located in the center and is exposed to the traffic. St. Mary Church (Fig. 2) and the "Bear tower" (Fig. 3) are located in the center of Jajce. The buildings from Jajce are located at less than three kilometers far from the factory for silica treatment. The factory use coal and oil as main 
energy sources. The factory is working since Austro-Hungarian period.

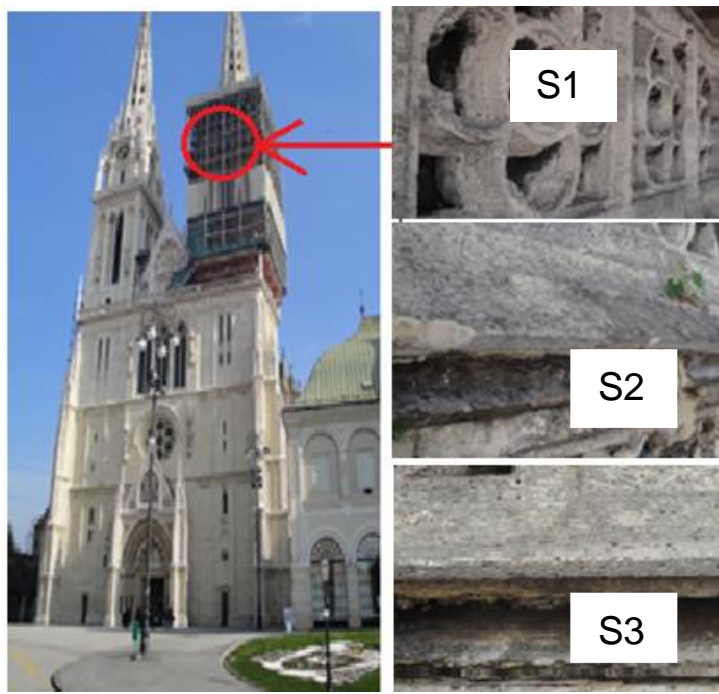

Fig.1. Cathedral of Mary's Ascension (Zagreb).

In the center of Jajce the traffic is limited and the main energy source for domestic heating is firewood. It can be assumed that the main pollution source comes from combustion process like coal and wood burning.

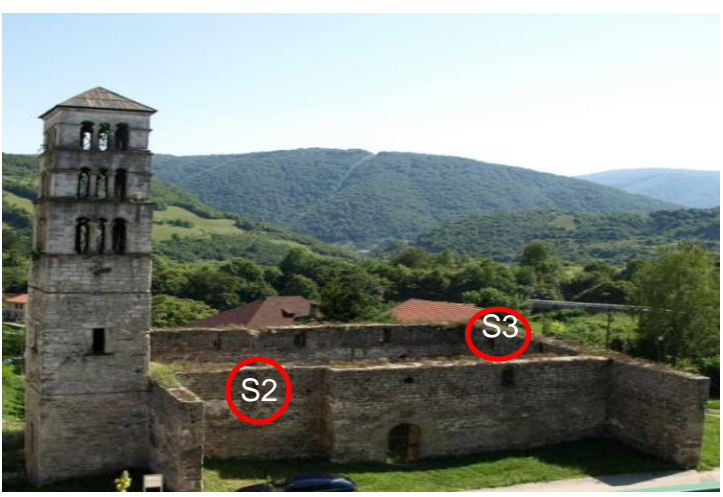

Fig.2. St. Mary Church (Jajce).

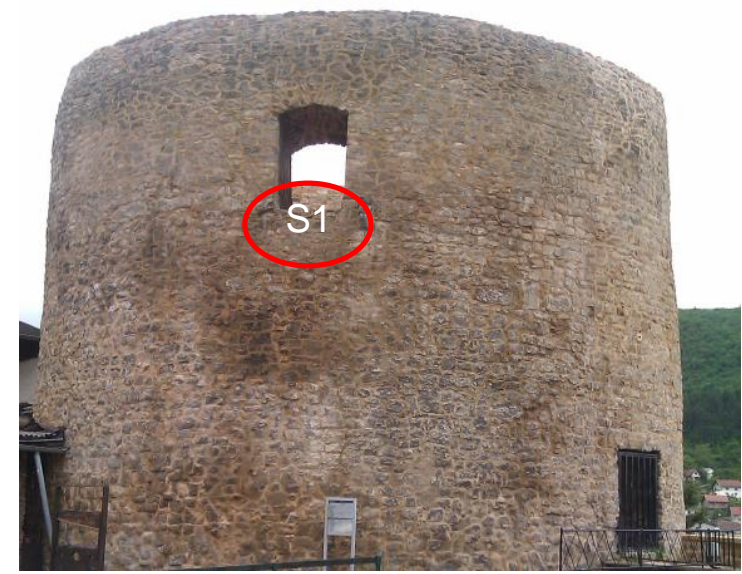

Fig.3. "Bear tower" (Jajce).
The analysis of trace metals from BCs sampled at different monuments was carried out with ICP-MS. Prior the analysis the samples were destroyed in the microwave oven by total digestion with the mixture of $\mathrm{HNO}_{3}, \mathrm{HCL}$ and HF (4:1:1). After the digestion the solution was diluted to the concentration optimal for HRICP-MS measurement. The quality of the measurements is checked with simultaneously digestion and measurement of certificated material.

\section{Results and discussion}

Since the purpose of this work was to identify the trace metals deposited from atmospheric aerosols on carbonate surfaces, the concentration of some trace metals measured in BCs samples from both sides are normalized to the concentrations of the same trace metals in unexposed limestone substrate (Fig. 4). The results highlight different chemical composition between the substrate and the black crust. Great number of trace metals detected in all studied BSc show enrichment in comparison to the background substrate.
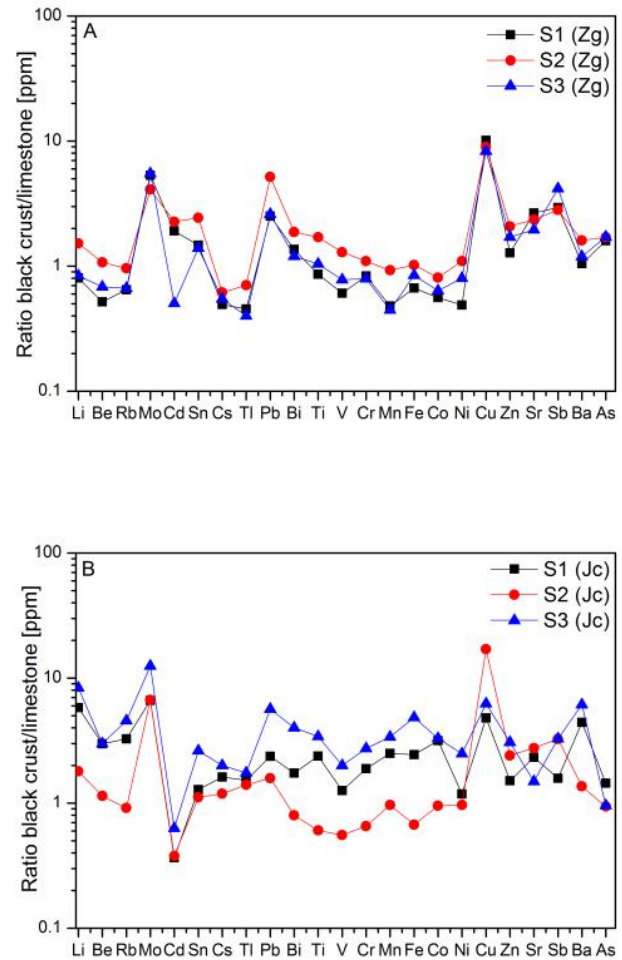

Fig.4. Concentration of metals in BCs from a) Zagreb and b) from Jajce normalized to those of limestone.

The samples from Zagreb (Fig. 4a) shows enrichment in some trace elements with respect to the substrate. This elements include Mo, Cd, $\mathrm{Sn}, \mathrm{Pb}, \mathrm{Bi}, \mathrm{Cu}, \mathrm{Zn}, \mathrm{Sr}, \mathrm{Sb}, \mathrm{Ba}$ and $\mathrm{As}$. The enrichment factor for this element ranging 
between 2-10: Cu up to 10, $\mathrm{Pb}$ and $\mathrm{Mo}$ up to 5, $\mathrm{Sb}$ up to $4, \mathrm{Sr}$ up to $3 \mathrm{Zn}, \mathrm{Cd}, \mathrm{Sn}, \mathrm{Bi}, \mathrm{Ba}$ and $\mathrm{As}$ about 2. It can be seen that some elements such as $\mathrm{Ti}, \mathrm{V}, \mathrm{Cr}, \mathrm{Mn}$, and $\mathrm{Fe}$, present in high concentration in the BCs (Fig. 5), show limited enrichment factor below 1 . Therefore, it can be concluded that the presence of this elements in the BCs is conditioned by the dissolution of the underlying stone [8]. On the other hand, elements present in limited concentration in $\mathrm{BCs}$, reveal considerable enrichment: $\mathrm{Mo}, \mathrm{Pb}$, $\mathrm{Cu}, \mathrm{Sr}$ and $\mathrm{Sb}$. Trace metals such as $\mathrm{Pb}, \mathrm{As}$, $\mathrm{Cu}, \mathrm{Zn}, \mathrm{Cd}$ and $\mathrm{Ba}$ can be related to the traffic pollution and the power plant [2]. Cu exhibits an enrichment factor above 10. Most $\mathrm{Cu}$ comes from the traffic because $\mathrm{Cu}$ is used as the main alloying element in the fabrications of outer and inner body panels, load floors and seat shells. This metal is a component of brake pads with content up to $16 \%$. Pb emissions are nowdays caused mainly by wear rather than fuel. Sb have enrichment factor above 4 . This metalloid is a component of brake linings such as the Mo. In addition Sb-dialkyl dithiocarbamaters are used as additives to greases and some types of oil. Antimony trioxide is used as retardant in vulcanization of rubber. Due to the absence of industry in Zagreb, enrichment of trace metals in the BCs from the Cathedral can be mainly attributed to the air pollution produced by traffic, domestic heating, and thermal power plants [9].

The samples from Jajce show enrichments in some elements with respect to the substrate as well (Fig 4b). The enrichment depends especially on the pollution source, and on the side from which the samples are taken. At the side of St. Mary Church which is turned to the main road (west side, S3) that leads out of the city and to the settlement "Bare", high enrichment factors of some anthropogenic elements is observed ( $\mathrm{Mo}, \mathrm{Pb}, \mathrm{Bi}, \mathrm{V}, \mathrm{Cr}, \mathrm{Mn}$, $\mathrm{Co}, \mathrm{Ni}, \mathrm{Cu}, \mathrm{Ba}$ ). "Bear tower" is turned to the same side but recent restauration works have influenced the enrichment factor. The samples taken from the western side from St. Mary Church (S3) and sample from "Bear" tower (western side, S1) show enrichment in almost all measured elements. Only a small fraction of heavy metals can be attributed to the migration from the substrate $(\mathrm{Rb}, \mathrm{Bi}, \mathrm{Ti}, \mathrm{V}, \mathrm{Cr}, \mathrm{Mn}, \mathrm{Fe}$, Co and $\mathrm{Ni}$ ), which is mainly characteristic for the sample taken from the northern side (S2) of St. Mary Church. The high enrichment factor of $\mathrm{Pb}$ (2-6), Zn (2-3), Cu (5-6), Cr (2-3), Ni (2-3), Sb (2-3) and V (1-2) found in the sample from the western side from St. Mary Church (S3) and sample from "Bear tower" (western side, S1) may be attributed to the direct exposure to the vehicular emission and to the friction of mechanical parts of vehicles [10]. Because of the sheltered positon of the northern sampling site (S2) of the St. Mary Church, the lowest enrichment factors are observed in this sample. The concentration of some heavy metals in all samples from Jajce are not normally distributed; Be $(p=0.014)$, Mo $(p=0.02)$, Sb $(p=0.02)$, As $(p=0.04)$ which can indicate that different pollution sources are present. These metals are present in combustion product of most coals [11]. Trace elements such as V, Zn, Mo, TI and $\mathrm{Pb}$ which are enriched in almost all samples from Jajce can be associated with the coal combustion products [12]. $\mathrm{V}$ can also be attributed to oil combustion [8]. Cu concentration in the samples from Jajce is normally distributed $(p=0.841)$ which means that almost all Cu comes from the same source, namely from traffic.

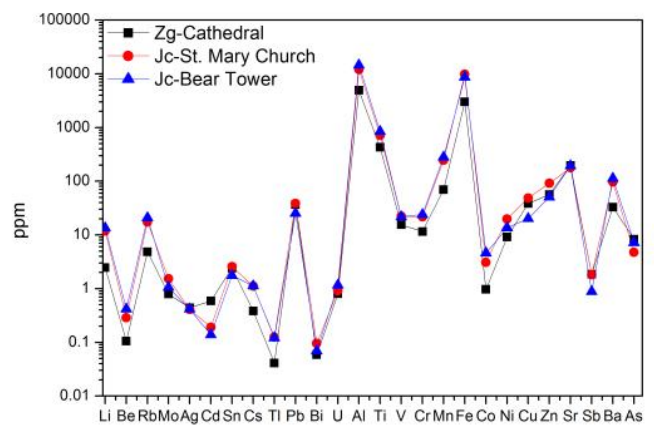

Fig.5. Average concentration of measured trace elements in BCs samples from Zagreb and Jajce.

\section{Conclusion}

In this study, BCs samples and the substrates collected from different monuments located in the cities of Zagreb and Jajce were analyzed for trace metals content. The enrichment factor observed in all samples indicated that the trace metals composition of the black crust is greatly influenced by the different pollution sources of the cities. The concentration of most trace metals in the samples from BCs collected from Jajce where particularly high, as a result of the combination of various anthropogenic sources and the age of monuments. The BCs samples from Zagreb shows a different enrichment factor in trace metals, indicating that atmospheric pollution is mainly due to the road traffic.

\section{Acknowledgements}

This work is supported by the project "The Sulphur and Carbon Dynamics in the Sea and Fresh-Water environment" (IP-11-2013-1205 SPHERE). 


\section{References}

[1] C. Sáiz-Jiménez, \& B. Hermosin,. Black crusts in the European built environment, Corrosion Reviews, 22(5-6), 381-394 (2004); doi: 10.1515/CORRREV.2004.22.5-6.381

[2] G. G. Amoroso, \& V. FassinaStone, decay and conservation: atmospheric pollution, cleaning, consolidation and protection: Elsevier Science Publishers (1983).

[3] A. BONAZZA, C, SABBIONI, N. GHEDINI, \& G. $\mathrm{GOBBI}$, . Blackening as major atmospheric pollution effect on monuments. Pollution atmosphérique, 49(OCT), 7-12, (2007).

[4] N. Prieto-Taboada, I. Ibarrondo, O. GómezLaserna, I. Martinez-Arkarazo, M.A. Olazabal \& J.M. Madariaga, Buildings as repositories of hazardous pollutants of anthropogenic origin, Journal of hazardous materials, 248, 451-460 (2013); doi: 10.1016/j.jhazmat.2013.01.008

[5] P. Maravelaki-Kalaitzaki, \& G. Biscontin, Origin, characteristics and morphology of weathering crusts on Istria stone in Venice, Atmospheric Environment, 33(11), 1699-1709 (1999); doi: 10.1016/S1352-2310(98)00263-5

[6] J. S. Sánchez, J. V. Romaní, \& C.

AlvesDeposition of particles on gypsum-rich coatings of historic buildings in urban and rural environments. Construction and Building Materials, 25(2), 813-822 (2011); doi: 10.1016/j.conbuildmat.2010.07.001

[7] D. Barca, V. Comite, C. M. Belfiore, A. Bonazza, M. F La Russa, S. A. Ruffolo, C. Sabbioni, Impact of air pollution in deterioration of carbonate building materials in Italian urban environments. Applied Geochemistry, 48, 122-131 (2014); doi: 10.1016/j.apgeochem.2014.07.002

[8] C. Sabbioni, \& G. Zappia, Atmospheric-derived element tracers on damaged stone. Science of the total environment, 126(1-2), 35-48 (1992); doi: 10.1016/0048-9697(92)90482-8

[9] F. Fujiwara, R. J. Rebagliati, L. Dawidowski, D. Gómez, G. Polla, V. Pereyra, \& P. Smichowski, Spatial and chemical patterns of size fractionated road dust collected in a megacitiy, Atmospheric Environment, 45(8), 1497-1505 (2011);doi: 10.1016/j.atmosenv.2010.12.053

[10] C. Rodriguez-Navarro, \& E. Sebastian, Role of particulate matter from vehicle exhaust on porous building stones (limestone) sulfation, Science of the total environment, 187(2), 79-91 (1996); doi: 10.1016/0048-9697(96)05124-8

[11] M. Xu, R. Yan, C. Zheng, Y. Qiao, J. Han, \& C. Sheng, Status of trace element emission in a coal combustion process: a review. Fuel Processing Technology, 85(2), 215-237 (2004);doi: 10.1016/S0378-3820(03)00174-7

[12] A. Deonarine, A. Kolker, \& M. Doughten, Trace elements in coal ash: US Department of the Interior, US Geological Survey (2015). 